should also be considered in patients with inadequate clinical response to monotherapy (ESC/ERS 2009). We aim to assess the use of modern advance treatments in 'real-life' patients and their impact on survival.

Methods A retrospective review of all incident cases of idiopathic, heritable and anorexigen-associated PAH diagnosed between 1st January 2001 and 31st December 2009 in our unit. Baseline and follow-up data were collected from case notes and local pulmonary hypertension database.

Results 94 incident cases were diagnosed ( $62 \%$ female) with median age of 63 years. $36 \%(n=34)$ of patients were on combination therapy. All except one patient were started on monotherapy, with second agent added at later stage. The median time from initiation of monotherapy to introduction of the second agent was 244 days. $25 \%$ had prostanoids; $51 \%$ endothelin receptor antagonists and $81 \%$ phosphodiesterase type- 5 inhibitor at some point of their treatment. The median survival is 5.63 years. We performed further analysis on the 28 patients who have died by censor date. Only seven patients were on prostanoids and eight patients on combination therapy. Possible explanations for low proportions of dead patients on prostanoids and/or combination therapy are outlined in Abstract P31 Table 1.

Abstract P31 Table 1 Possible explanations why prostanoids or combination therapies were not started

\begin{tabular}{ll}
\hline & Number of dead patients (total=28) \\
\hline Already on prostanoids & 7 \\
$\begin{array}{l}\text { Died from unrelated causes } \\
\text { Prostanoids considered but felt inappropriate, } \\
\text { for palliation only }\end{array}$ & 6 \\
$\begin{array}{l}\text { No documented explanation } \\
\begin{array}{l}\text { Treatment optimised less than } 4 \text { months } \\
\text { before death }\end{array}\end{array}$ & 3 \\
$\begin{array}{l}\text { Clinically improving at last clinic review } \\
\text { before death }\end{array}$ & 2 \\
$\begin{array}{l}\text { Sudden unexpected death } \\
\text { Lost to follow up }\end{array}$ & 1 \\
Poor compliance, frequent non-attendance of \\
clinics
\end{tabular}

Conclusion Our results demonstrate improved survival compared to pre-advance therapy era. Apart from proven efficacy of various $\mathrm{PAH}$ specific treatment, several other factors may also influence the treatment decision for individual patient.

\section{P32 DELIVERING PULMONARY HYPERTENSION SERVICES-5 YEAR EXPERIENCE FROM A SATELLITE CENTRE}

doi:10.1136/thx.2010.150961.32

${ }^{1} \mathrm{~S}$ Sturney, ${ }^{2} \mathrm{~S}$ Reddecliffe, ${ }^{1} \mathrm{H}$ Davies, ${ }^{1} \mathrm{G}$ Robinson, ${ }^{1} \mathrm{~J}$ Easaw, ${ }^{1} \mathrm{~J}$ Suntharalingam, ${ }^{2} \mathrm{G}$ Coghlan. ${ }^{1}$ Royal United Hospital, Bath, UK; ${ }^{2}$ Royal Free Hospital, London, UK

Introduction There are currently no National Commissioning Group (NCG) designated Pulmonary Hypertension ( $\mathrm{PH}$ ) centres in the South West. As a result patients can travel up to 300 miles to access specialist care. In 2005, a satellite service was developed at the Royal United Hospital (RUH), Bath in conjunction with the Royal Free, London. Initially the service simply provided a follow up service for patients known to the Royal Free. Since 2007 the service has fully investigated and managed new referrals locally, with supervision from the Royal Free. Patients have typically only needed to travel to an NCG centre for initiation of parenteral prostanoid therapy or for pulmonary endarterectomy (PEA).
Aim This abstract describes the first 5 years of activity by the RUH satellite PH service.

Results As of 1st July 2010, 147 new referrals have been received, increasing steadily from 7/year in 2005-2006 to 57/year in 2009-2010. Referrals originated from 7 specialities across 12 PCTs, with $48.6 \%$ from outside the immediate catchment area. 43 patients were diagnosed with Pulmonary Arterial Hypertension (PAH) (including 34 with Connective Tissue Disease-related PAH), 21 with Chronic Thromboembolic Pulmonary Hypertension (CTEPH) (including 15 referred for PEA surgery), 13 with $\mathrm{PH}$ associated with lung disease, 24 with $\mathrm{PH}$ associated with left heart disease. $\mathrm{PH}$ was excluded in 45 cases. 62 have received $\mathrm{PH}$-specific medication; 38 monotherapy and 24 combination therapy (including 7 intravenous, 1 subcutaneous and 2 nebulised prostanoid therapy). Survival data for the 38 treated WHO Group 1 PAH patients compares favourably with published data for NCG designated centres; $89.5 \%$ at 1 year (95\% CI $74.2 \%$ to $96.6 \%$ ), $82.3 \%$ at 2 years (95\% CI $65.9 \%$ to $92.2 \%$ ) and $77.2 \%$ at 3 years ( $95 \%$ CI $60.3 \%$ to $88.6 \%$ ). 489 journeys were made to the RUH and only 60 to NCG centres, saving approximately 56000 patient miles. A recent patient survey indicated high levels of satisfaction, with $94.4 \%$ stating they would rather continue follow-up locally.

Discussion These results suggest that a comprehensive $\mathrm{PH}$ specialist service can be delivered locally in a way that is more convenient for patients whilst still maintaining national standards of care.

\section{P33 \\ IRON DEFICIENCY INDEPENDENTLY PREDICTS SURVIVAL IN IDIOPATHIC PULMONARY ARTERIAL HYPERTENSION}

doi:10.1136/thx.2010.150961.33

CJ Rhodes, LS Howard, M Busbridge, D Ashby, E Kondili, JSR Gibbs, J Wharton, MR Wilkins. Imperial College London, London, UK

Objectives Characterise the iron status of patients with idiopathic pulmonary arterial hypertension (IPAH) and its clinical importance.

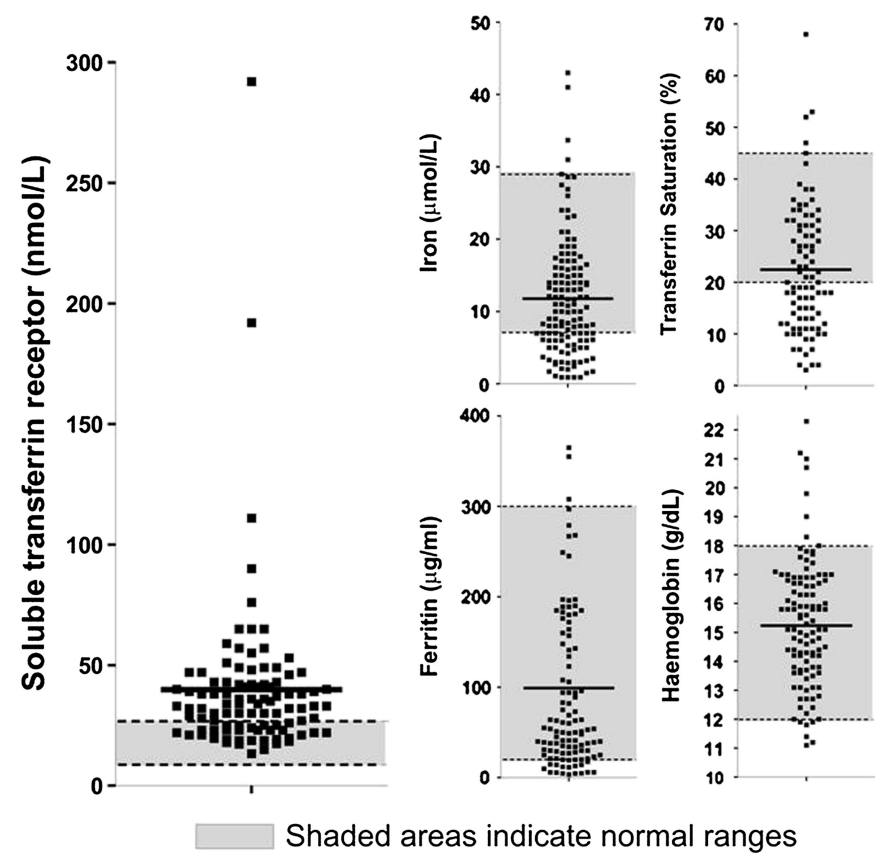

Abstract P33 Figure 1 